\title{
SCIENCE
}

FRIDAY, MARCH 2, 1888.

At the last meeting of the. Washington Philosophical Society, Mr. William Hallock presented a very noteworthy communication upon the formation of fusible alloys. Wood's alloy, which melts at about $64^{\circ} \mathrm{C}$., is composed of lead, tin, cadmium, and bismuth, and the lowest melting-point among its constituents is $230^{\circ} \mathrm{C}$. Mr. Hallock finds, however, that when the several metals are mixed together in filings, and exposed for twenty-four hours to the heat of an ordinary water-bath, the alloy is produced, and the mass becomes fluid. So, also, when freshly cut slices of sodium and potassium are simply pressed together at ordinary temperatures, liquefaction at once begins, and the fluid alloy is formed. In brief, it seems probable that the phenomena may be generalized, and that all fusible alloys may be obtained from their solid constituents at temperatures very slightly in excess of the melting-points of the compounds. Previous fluidity of either constituent is not necessary. It will be seen that these results bear directly upon the work reported by Spring, who claimed to obtain fusible alloys by pressure alone, but who neglected to prove that the temperature of his materials never at any point reached $70^{\circ} \mathrm{C}$. Probably, also, Mr. Hallock's discovery may have decided bearing upon certain questions of molecular dynamics. His results are extraordinary, but it is more extraordinary that the phenomena had escaped notice hitherto.

A WRITER on the psychology of acting, in Longman's Magazine, has introduced the inductive method into the solution of problems connected with the histrionic art. The question has often been debated, whether the effective personation of a part requires a real experience of the emotions concerned, so that it is acting only in the sense of artificially exciting a series of emotions; or whether the whole performance is a piece of art, with the emotions, or what to the audience shall stand for such, as entirely assumed as is the costume. The writer in question has addressed a circular upon this and allied topics to members of the actor's profession, and the majority of his answers decide in favor of the real emotion. The emotion of grief is taken as the typical one; and here the sad expression is, as a rule, not put on, but is the counterpart of a real sympathetic state. Real tears flow, often to the extent of interfering with distinct articulation; nor can the impression be at once shaken off upon leaving the stage. A pertinent instance is cited of an actor and an actress having to perform a touching scene many scores of times, and each night resolving ' not to make fools of themselves' by sobs and tears; but each night they broke down, and showed the reality of their emotions. Another actress is reported as saying that if she could play whatever piece most suited her humor each evening, her task would be a much easier one. The general verdict is, that the greatest success is produced by a real emotion. If one regards the performances of persons in the hypnotic condition as 'acting' in this sense, this is precisely the conclusion that the psychologist would expect. It is, however, not a universal experience, some actors testifying that their performance is almost entirely a planned, cool, intellectual artifice ; nor are such actors absent among the 'stars' of the profession. That the assumption of a rôle can by repetition become sufficiently assimilated to be taken up by the automatic self, is shown by the experience of a very celebrated actress, who played the 'potion scene' in 'Romeo and Juliet' without knowing it, and could only with the greatest difficulty be prevented from playing the scene over again, so confident was she that she had not played it.
The Committee on the geology of Rhode Island of the Providence Franklin Society has issued a valuable report on the geology of Rhode Island, including a useful bibliography of this subject, and setting forth briefly the various attempts made by the society to organize a thorough topographical and geological survey of the State. The committee was appointed in 1883 , and we quote from its valuable report the following general remarks, which show the object of the work undertaken by the committee: "Our chief purpose has been to bring to the notice of the Franklin Society what has already been learned about the geology of Rhode Island. We have attempted little original investigation, but have tried to lay the foundations essential to future progress. The necessity for a collation of authorities is apparent to one who seeks to gain a clear idea of the geology of Rhode Island. Information is scattered through many publications. The Franklin Society endeavored to secure a new survey of the State in $1875-76$, and again made an effort for a topographical survey in $1885-86$; but thus far nothing has been accomplished. This report is published as the best contribution the society can make to the cause, - a step towards a complete survey; for a knowledge of what has already been learned is the proper foundation on which to build." It is to be hoped that the unceasing endeavors of the society to undertake a survey on a similar plan to that of Massachusetts, in co-operation with the United States Geological Survey, will be successful. In I 885 Governor Brown sent a message to the Assembly, commending such a plan, which involved two annual payments- of three thousand dollars, but the Assembly did not act on it. The present publication, which is a valuable help to all students of the subject of the geology and geography of New England, we hope will help to show the necessity of undertaking a thorough survey.

\section{IS THE RAINFALL INCREASING UPON THE PLAINS?}

To most of the inhabitants of that broad, billowy expanse which stretches from the Missouri to the Rocky Mountains, and from Canada to the Rio Grande, this question may seem unnecessary. It has so long been assumed by them as an axiom that the rainfall is increasing, that the opening of the question to discussion may appear like questioning the Copernican system. They have seen the frontier of settlement moving steadily westward, passing successively the limits set for it. Thirty years ago all the country west of the Missouri was considered as the 'Great American Desert,' in which, without irrigation, agriculture was an impossibility. But the stream of immigration has swept, with each succeeding year, farther and farther up the slope of the plains, driving the border of the desert before it. The 98 th meridian was set as the boundary which the farmer could not pass, but now millions of acres are under cultivation beyond it; then the Iooth meridian, but in Kansas and Nebraska the farms stretch scores of miles farther westward.

Progress has not, however, been uniform. Seasons of drought have checked it, and have depopulated temporarily large areas; but the settlers have returned to the charge, and have invariably won the day in the end.

To-day the cereals are being cultivated in Kansas, without irri gation, nearly to the west boundary of the State, in regions where the annual rainfall twenty years ago was less than twenty inches, - a region which at that time, as was generally agreed, could be rendered productive only by artificial watering. How has this been brought about? Have settlement and tree-planting induced greater rainfall, as is almost universally believed in this region, or are other causes involved?

Of course, if this westward extension of settlement has become 